\title{
Decisiones judiciales como políticas públicas
}

\section{Judicial decisions and public policies}

Recibido 11/08/2015 - Aprobado 28//10/2015

Enrique Dussán Cabrera

Estudiante de la Maestría en Derecho Público de la Universidad Surcolombiana

Grupo de Investigación: Nuevas Visiones del Derecho

Magistrado del Tribunal Contencioso Administrativo del Huila endusca@hotmail.com

\section{RESUMEN}

Este artículo presenta la temática de las políticas públicas. Se definen, y se alude a sus elementos, el ciclo, los actores, especialmente el juez como actor que ha ingresado con ímpetu en el tópico de las políticas públicas. Igualmente se refiere a la utilización de los recursos de las políticas públicas de manera sostenible, las normas y su relación con las políticas públicas y la incidencia de las decisiones judiciales en ellas, lo que ha generado tensión en el sistema político entre el arbitrio judicial y el arbitrio político y cómo los jueces adquieren un grado alto de responsabilidad en la motivación de sus providencias dado que en la mayoría de los casos terminan ordenando, directa o indirectamente, la fijación de políticas públicas.

\section{PALABRAS CLAVE}

Elementos de políticas públicas, Consejo de Estado, normas jurídicas, decisiones judiciales.

\section{ABSTRACT}

This article presents the theme of policies. It defines its concept, elements, cicle, participants and especially it presents the judge as an actor who has entered to this topic with impetus. Additionally, this article refers to the usage of policies' resources in a sustainable way, laws and their relation to policies, and judicial decisions' impact on them. Therefore a tension is generated in the political system between the judicial referee and the political referee, and how judges acquire a high level of responsability on the justification of their providences on most cases on which they end up ordering, direct or indirectly, the assumption of policies.

\section{KEYWORDS}

Elements of public policy, the State Council, legal regulations, judicial decisions.

\section{INTRODUCCIÓN}

El presente escrito hace parte de la investigación sobre Políticas Públicas en el Consejo de Estado
Colombiano como Tribunal Supremo de lo Contencioso Administrativo, cuya finalidad es establecer si en las sentencias proferidas sobre «devolución» de la personería jurídica a la Unión Patriótica 
(sentencia del 4 de julio de 2013); la concesión de nuevos canales de televisión de operación privada (fallo del 27 de marzo de 2014); y la descontaminación del río Bogotá (decisión del 28 de marzo de 2014), crea, ordena crear o establece políticas públicas de carácter político, económico y ecológico, respectivamente y a su vez el fundamento teórico jurídico que cimienta las fuentes de derecho para tal finalidad.

En consecuencia como referente de la investigación, se identifican las definiciones, significaciones 0 conceptos de políticas públicas, se exponen enunciaciones de lo que no son políticas públicas para enfatizar el significado de lo que son; igualmente se alude a los elementos que identifican, las políticas públicas y que constituyen su naturaleza o esencia que las caracteriza, sin los cuales no son o dejan de serlo para convertirse en otros asuntos de los que el Estado atiende.

Se expone el ciclo de las políticas públicas, que más que componente esencial, ha sido una conceptualización o herramienta para su análisis y que permite establecer su entrelace secuencial de la actividad previa, su manifestación y ejecución de las políticas públicas.

Se alude también a los actores de las políticas públicas y cómo, del principal que era el gobierno, han ingresado nuevos actores como son los jueces, con mucho ímpetu y cuya actividad es el objeto central de la investigación. También se exponen los recursos necesarios que se utilizan en las políticas públicas donde la información es un recurso trascendente y su utilización debe obedecer a una sostenibilidad y conservación del ambiente. Como elemento del Estado social de derecho se indica la normatividad jurídica y su relación con las políticas públicas, para finalmente aludir a la interacción de las decisiones judiciales con relación a políticas públicas y la incidencia en la agenda gubernamental que impacta la gobernanza.

La metodología utilizada para la elaboración del presente artículo ha conllevado la revisión, lectura y estudio de libros, artículos, revistas y papers, con una perspectiva analítica, crítica e interpretativa so- bre políticas públicas, para conceptualizar lo que aquí se expone, previa elaboración de notas textuales iniciales, mediante la selección de los aspectos principales que los escritores y doctrinantes del tema han expuesto, proponiendo conceptos adicionales para los efectos de la finalidad que la investigación principal pretende.

\section{1. ¿QUÉ SON LAS POLÍTICAS PÚBLICAS?}

Las políticas públicas, como concepto o definición, ha tenido en la literatura especializada, una gran variedad de enunciaciones, significados o asertos, que los teóricos y analistas del tema han venido desarrollando, para determinar la mejor idea que represente 0 constituya un significado integrador y bien característico.

Históricamente se ha realizado una diferenciación de lo que se entiende por política, y política pública. Roth (2002) expone que para definir el concepto de política pública hay una dificultad semántica que se presenta en el español con el término política, indica que el idioma inglés distingue, la política concebida como el ámbito del gobierno de las sociedades humanas (polity en inglés); igualmente como la actividad de organización y lucha por el control del poder (politics en inglés); y, finalmente, la política como designación de los propósitos y programas de las autoridades públicas (policy en inglés), acepción esta que es la que alude a políticas públicas (p.25), Cita, a guisa de ejemplo, seis definiciones de autores extranjeros y dos de autores colombianos que definen políticas públicas de diversas maneras. Concluye considerando que política pública es:

Un conjunto conformado por uno o varios objetivos colectivos considerados necesarios 0 deseables y por medio de acciones que son tratados, por lo menos parcialmente, por una institución u organización gubernamental con la finalidad de orientar el comportamiento de actores individuales o colectivos para modificar una situación percibida como insatisfactoria o problemática (p. 27).

El anterior concepto permite entender que toda actuación de las instituciones gubernamentales 
constituyen políticas públicas, como lo comenta y critica Cuervo (2007), y que desde luego no lo es, dado que el Estado en general y el gobierno en particular, realizan diversas actividades que buscan modificar situaciones insatisfactorias de comunidades o individuos y tales realizaciones no son políticas públicas.

Por su parte, Maggiolo y Perozo (2007, p. 375), en un cuadro de comparación conceptual, reseñan algunas definiciones de varios autores (Rose- 1984; Subirats-1989; Lahera-1999; Repetto-2000; y Piñango2003), para luego caracterizar las políticas públicas, «como un proceso de concertación Estado-Sociedad, mediante el examen de la interacción entre estos, para llegar a un punto de acuerdo, las políticas públicas», estableciendo como principales conclusiones que:

Son el resultado de actos de confrontación/acuerdo entre representantes estatales y sociales, que enfrentan nudos críticos, situaciones conflictivas y restricciones normatizadas, donde por su naturaleza política el Estado está implícito, pero la sociedad requiere de cierto empoderamiento social y canales de comunicación efectivos que avalen una sana y estrecha relación Estado.

De donde se colige que la existencia de las políticas públicas se dan o surgen por las confrontaciones o conflictos entre el Estado y la Sociedad y son las situaciones de mayor intensidad o ruido las que generan políticas públicas, pues se requiere darle solución o minimizar su impacto, pues de no hacerlo puede amenazar al gobierno; conceptualizando entonces, que Estado y Sociedad son entes diversos y prácticamente antagónicos, pero a su vez complementarios, pues la creación o adopción de políticas públicas, son las salidas o soluciones a dicho enfrentamiento y la forma política social de dar solución satisfactoria a dicha contradicción.

Ahora bien, Cuervo (2007, p. 73), expone que en revisión crítica de las definiciones de políticas públicas, dichas conceptualizaciones son vagas e imprecisas «que no dicen nada de lo que es realmente una política pública», pues «no permite diferenciar las políticas públicas de otras acciones del gobierno y del Estado que no constituyen una acción en la lógica de la política pública», por lo que citando varios autores, critica la enunciación que equipara el concepto como «un programa de acción gubernamental en un sector de la sociedad», y enfatiza que eso no es política pública, pues se asimilaría a un plan de desarrollo, un plan de ordenamiento territorial o se convierte en sinónimo de política gubernamental o hasta sería confundida con la misma ley o cualquier actividad del gobierno, sin quedar claramente determinado lo que es realmente política pública, en tanto establece lo que debe entenderse por políticas públicas:

Las actuaciones de los gobiernos, por lo general, que están orientadas a resolver demandas sociales, y que pueden contar con el concurso de otros actores institucionales, como los congresos y los poderes judiciales, e incluso sectores organizados de la sociedad civil -incluidos los agentes de mercado-, que suponen una serie de procesos de mediación política y social donde se combinan lo técnico y lo político para corregir un desajuste social (p. 93).

Por tanto, es importante según su concepto, la mediación política y social, como elemento destacado de las políticas públicas, para corregir un desajuste social, término este que supone entonces una sociedad «mecánica» a la que habría que ajustarle una pieza, como cuando se aprieta un tornillo de una máquina que no funciona bien, lo que se critica por no ser una conceptualización de la sociedad actual, pues dicho símil era más propio de la era industrial.

Por su parte, Subirats, Knoepfel, Larrue y Varone, (2010, p. 38), después de reseñar varias definiciones, enfatizan que algunas de ellas acentúan algún factor, bien sea el de los poderes públicos, los problemas públicos a resolver, las soluciones estatales adoptadas, o un "rompecabezas» (puzzle), para finalmente establecer una "definición analítica», e indicar que política pública es «una serie de decisiones o de acciones, intencionalmente coherentes, tomadas por diferentes actores, públicos y a veces no públicos -cuyos recursos, nexos institucionales e intereses varían- a fin de resolver de manera puntual un problema políticamente definido como 
colectivo». Definición aceptada por cuanto identifica el proceso de construcción como el producto final de ese proceso solucionador de la situación o problema público.

Por su parte, Velásquez (2009), previa agrupación de diversas definiciones, invita a que se asuma el riesgo (que denomina académico) de «producir una definición que, a manera de macro-concepto, y en lo posible de manera neutra y libre de valores, comprenda la esencia de lo que es la política pública y permita su comprensión» (p. 156), definiéndola así:

Un proceso integrador de decisiones, acciones, inacciones, acuerdos e instrumentos, adelantado por autoridades públicas con la participación eventual de los particulares, y encaminado a solucionar 0 prevenir una situación definida como problemática. La política pública hace parte de un ambiente determinado del cual se nutre y al cual pretende modificar o mantener.

Se identifica con lo anterior para agrupar las decisiones en el proceso de adopción por parte de autoridad pública, actor determinante del producto solucionador del problema o realidad a modificar.

Así mismo, La normatividad nacional ha establecido un concepto sobre políticas públicas, para los efectos que dicha norma pretende, y es así que en el artículo 201 de la ley 1098 de 2006 (Por la cual se expide el Código de la Infancia y la Adolescencia) establece:

ARTÍCULO 201. DEFINICIÓN DE POLÍTICAS PÚBLICAS DE INFANCIA Y ADOLESCENCIA. Para los efectos de esta ley, se entienden por políticas públicas de infancia y adolescencia, el conjunto de acciones que adelanta el Estado, con la participación de la sociedad y de la familia, para garantizar la protección integral de los niños, las niñas y los adolescentes.

Las políticas públicas se ejecutan a través de la formulación, implementación, evaluación y seguimiento de planes, programas, proyectos, y estrategias.

Como se evidencia, más que el proceso previo de adopción de las políticas públicas, denota es la ac- tividad del Estado en pro de la protección de la población objeto de la ley. A su vez, el Ministerio de Salud y Protección Social (2012) al hacer las políticas públicas para las familias colombianas establece que las políticas públicas son:

El producto de la interlocución entre el Estado y la sociedad civil que actúa a través de sus organizaciones y de las personas a título puramente individual. Las políticas públicas son el resultado de una mediación y a su vez son las mediadoras entre el Estado y sus beneficiarios y beneficiarias.

Sin embargo, esta definición estatal, no construye ni establece un concepto completo de políticas públicas, pues hace prevalecer el producto o resultado como consecuencia de una mediación de lo cual no queda claro quien la realiza y pareciera que el Estado y los beneficiarios son elementos totalmente apartes y autónomos pero enfrentados, lo que no necesariamente sucede en el proceso de la política pública.

La administración distrital de Bogotá, (Alcaldía de Bogotá, s.f.), en "Guía para la formulación, implementación y evaluación de políticas públicas distritales», plantea la política pública como una forma diferente de distribución del poder para la repartición de bienes o servicios. En efecto establece la siguiente definición:

La política pública entendida como el conjunto de decisiones políticas y acciones estratégicas que llevan a la transformación de una realidad social, que tanto los ciudadanos y ciudadanas como quienes representan al Estado han determinado como importante o prioritaria de transformar, dado que subsisten en ella condiciones de desequilibrio y desigualdad que afectan la calidad de vida. La política pública plantea una distribución diferente de lo existente, en especial y de manera estructural, del poder y su relación con la distribución de los bienes o servicios, y de estos en atención a la materialización de los derechos individuales y colectivos teniendo en cuenta contextos y territorios políticos y sociales.

Con dicho concepto se enfatizan los problemas 0 situaciones a solucionar, como problemas políticos, 
esto es como asuntos de poder y por tanto el diseño de las políticas públicas son contenidos, manifestaciones y manejo de ese poder político.

De igual manera, Ayala (2014, p. 6), determina que las políticas públicas son respuestas que da el Estado en forma de normas, instituciones, prestaciones, bienes o servicios, como acciones, inacciones, 0 acuerdos, resultado de un proceso integrador adelantado entre autoridades públicas con la participación eventual de los particulares, con fines puntuales a demandas sociales, respuestas que están ligadas directamente a la finalidad que tiene el Estado de solucionar o prevenir una situación definida como problemática.

El concepto de políticas públicas tiene diversas interpretaciones y variadas perspectivas, infiriéndose que son bienes o servicios socialmente útiles adoptados por el Estado, esencialmente por el gobierno, producto de decisiones de actores públicos-sociales que comprende varias actividades interdependientes, fundamentados en información y en la normatividad político-jurídica del Estado que responden a situaciones problemáticas de una comunidad o grupo social determinado, previamente agendadas.

\section{2. ¿QUÉ NO SON POLÍTICAS PÚBLICAS?}

Una forma de entender un concepto es detallando o describiendo lo que no es y el de políticas públicas también se puede razonar de esta manera. Varios autores han expresado lo que no constituye política pública para precisamente facilitar la descripción de lo que es, así, Vargas (1996, p. 44) expone que política pública no es igual a la ley 0 a la norma, tampoco es «exclusivamente política económica»; mucho menos una decisión aislada. Cuervo (2007) expone que «No todo lo que hace el Estado y el gobierno son políticas públicas. Política pública no necesariamente es sinónimo de acción gubernamental». Subirats et al (p. 43) expone que no son políticas públicas las decisiones 0 actividades únicas, incoherentes; las emprendidas por actores privados, las decisiones que no pasan de un estado puramente legislativo, así como las decisiones o actividades sin actos formales de implementación o sin objetivos puntuales.

Aguirre (2015, p. 4), dice que no es política pública «la que plantea que se beneficien unos excluyendo a otros»; igualmente que no se puede asimilar al documento que la contiene, como tampoco que es un mandato; "no es por tanto una ley, un decreto, una ordenanza o un acuerdo municipal y tampoco es un Plan de Desarrollo o una orden de la autoridad competente».

No es política pública, por tanto, el ejercicio general de la función pública o de la prestación de los servicios públicos realizados por el Estado, pues puede ser una manera particular y concreta de manifestarse pero su ejercicio habitual, corriente y universal no la constituye.

Tampoco es política pública las actividades realizadas por las empresas o los particulares en aras de solucionar problemas sociales generales o particulares de grupos determinados de población que en función de programas de responsabilidad social ejecutan y muestran; así mismo aquellos que en aras de obtener beneficios tributarios del ordena nacional, departamental o municipal, realizan y efectivamente lo reportan al Estado en las declaraciones tributarias respectiva.

\section{ELEMENTOS QUE CONFORMAN E IDENTIFI- CAN LAS POLÍTICAS PÚBLICAS}

Los elementos de las políticas públicas son las diversas partes o segmentos que la conforman y le dan su razón de ser. El conocimiento de los mismos tiene la importancia que facilita tanto su creación como su análisis. De los conceptos y definiciones antes presentados, se colige la existencia de varios elementos que las caracterizan, le dan identidad y permiten reconocerla y, a su vez, diferenciarla de otras actividades que realiza el Estado dentro de sus competencias constitucionales y legales.

Según Roth (2002, p. 27) existen cuatro elementos que identifican la política pública, a saber: «i). Implicación del gobierno; ii). Percepción de problemas; 
iii). Definiciones de objetivos; y iv). Proceso». Sin embargo, dichos elementos pueden ser encontrados en diversas actividades que realiza el Estado, las cuales no son políticas públicas, por ejemplo, la adopción de ayudas de parte del gobierno a una población que ha padecido de un desastre natural 0 producido por el hombre y respecto de la cual se pretende inicialmente facilitarle la supervivencia y el mínimo vital, luego de ocurrida la calamidad, desarrollando para tal finalidad los protocolos establecidos por la agencia perteneciente al Sistema Nacional de Información para la Gestión del Riesgo de Desastres, en este caso se cumple con todos los elementos antes indicados, pero dicha actividad no necesariamente es una política pública, pues obedece al cumplimiento del deber legal de auxilio o socorro que tiene el Estado. De ahí que tal descripción resulta insuficiente para caracterizar y tener por establecido la existencia de una política pública.

Varios autores, como Gómez (2014), Tassara (2014), entre otros, reconocen los elementos descritos por Roth, como componentes e integrantes de las políticas públicas y establecen que los mismos determinan que son una construcción social, dada la acción gubernamental y los actores sociales que intervienen, pero el hecho de ser una construcción social no es suficiente para identificar la existencia de una política pública en actuaciones del Estado 0 del gobierno, como se ha indicado.

Rincón (2014, p. 532), indica que aun cuando existe abundancia de textos que se relacionan con los elementos de las políticas públicas ${ }^{1}$, ninguno se detiene en estudiar de manera independiente cada fase de la política pública, la que a su vez constituyen procesos; y basándose en los señalamientos de Muller (2006. p.54) y Grau (2002: 37-45), expone que son cinco las fases de la adopción de una política pública, lo que a su vez son sus elementos característicos: i). La identificación del problema y formación de la agenda; ii). La formulación de las soluciones y toma de decisiones; iii). la Implementación de la política decidida; iv). La evaluación, que pone en perspectiva los resultados de la política implementada, y; v). El mantenimiento, revisión o terminación de la política.

Para Subirats (2010), la política pública establece como elementos constitutivos los siguientes:

a) La solución de un problema público. Existencia de una insatisfacción social, cuya solución requiere la acción del sector público.

b) Existencia de grupos-objetivo en el origen de un problema público. Grupos sociales cuyo comportamiento, se supone, genera el problema que se trata de resolver.

c) Coherencia al menos intencional. Presupone una base conceptual de partida; igualmente que las decisiones y las actividades que se llevan a cabo están relacionadas entre sí.

d) La existencia de diversas decisiones y actividades. Conjunto de acciones que van más allá de la decisión única o específica.

e) Programa de intervenciones. El conjunto de decisiones y acciones contienen acciones concretas e individualizadas.

f) Papel clave de los actores públicos. Las decisiones y acciones las toman y realizan los actores públicos desde esa condición.

g) Existencia de actos formales. Existencia de una fase de implementación de las medidas decididas.

h) Naturaleza más o menos obligatoria de las decisiones y actividades. Las formas de acción pública actualmente son tanto incentivadoras como coercitivas (p. 40).

1 Entre los que destacan: Grau (2002); Subirats (1989); Subirats y Gomá (1998); Álvarez (1992); Muller (2006); Dunn (1994); Urdaneta (2010); King don (1984); Aguilar (1994); Lindblom (1994); Arellano (1996); Klijn (1998); Lindblom (1994); Roth (2004 y 2007); Etzioni (1994); Aktouf (1998); Simón (1986); Chaqués (2004); Fleury (2002); Zurbriggen (2003); Dunn (1994); Dror (1994); y Ochoa (2007). 
De donde se infiere que lo que da el tinte para caracterizar las políticas públicas son el problema 0 asunto social de un grupo-objetivo que llega a la agenda del gobierno lo que lo convierte en problema 0 asunto público; donde a la par se identifican actores esenciales de las políticas públicas, de los cuales se expone un aparte posterior.

Ayala (2014, p. 8), establece que la política pública debe tener los siguientes elementos: «Una situación de facto que requiera una intervención estatal, el análisis integral de las posibles soluciones, acciones o decisiones puntuales, un proceso evaluativo de monitoreo que permita obtener unos resultados o unos objetivos claros de solución del conflicto, es decir de la demanda social».

Elementos que si bien son integrantes de las políticas públicas, el primero de los mencionados resulta insuficiente para darle la teñidura o naturaleza intrínseca de la política pública, pues siempre existen situaciones fácticas que requieren la intervención estatal y pese a su presencia las mismas no entran a la agenda del gobierno o del Estado lo que conlleva que no sea política pública.

Jiménez \& Soler (2013,), exponen que hay un relativo consenso en la comunidad académica e identifican como elementos que caracterizan una política pública los siguientes:

a) Un contenido, pues posee una concreción fenoménica de relevancia para la autoridad pública o para la solución de un problema social.

b) Un programa, que es una estructura relativamente permanente, articulada de los actos de la autoridad pública para la consecución de los objetivos propuestos.

c) Una orientación normativa o teleológica, pues la política pública expresa finalidades y preferencias de la autoridad pública que se concretan en normas jurídicas.

d) Un factor de coerción, pues la realización de la política pública se sustenta en la autoridad de que se halla investido el actor gubernamental y en ejercicio del poder político que conlleva el hacerse obedecer así sea por la fuerza; y

e) Una competencia social, que es la percepción de que la autoridad está legitimada para intervenir en el problema en beneficio de la sociedad y por ende que puede intervenir en la sociedad (p. 40).

Sin embargo, Santibáñez; Barra; \& Ortiz (2015, pp.1113), indican que los elementos de las políticas públicas son: i). Los problemas públicos; ii). La información; ii). La ideología, y; iv). El poder (autoridad); lo que conlleva que el consenso no se presente.

Ahora bien, dado que las políticas públicas son procesos interdependientes, desde su origen, el inicio, su creación y definición, como su ejecución y evaluación, en todo esas fases actúan varios elementos a saber: el asunto problemático social que es convertido en asunto-problema-público; el análisis de la información que realizan los actores, bien como grupo social beneficiario de la política pública, o el gobierno creador o ejecutor de la política pública, lo cual les da fundamento para su rol; el Estado y los actores sociales de toda índole que participan en su formación, decisión, ejecución y evaluación; la población objeto de la política pública; y el ordenamiento jurídico.

En consecuencia, los elementos de las políticas públicas lo integran: i). El Estado en general y particularmente el gobierno; ii). Las situaciones sociales problemáticas que se proyecta solucionar o minimizar, agendadas; iii). Los bienes o servicios concretos que se pretende distribuir, otorgar, entregar o dar; iv). Los actores público-sociales de diversa índole; v). Los procesos interdependientes, en acción; vi) La información como eje transversal siempre necesaria y presente en todo el ciclo y; vii). La normatividad político-jurídica del Estado en que se fundamentan.

\section{CICLO DE LAS POLÍTICAS PÚBLICAS}

El ciclo de las políticas públicas es el conjunto de fases, decisiones y ejecuciones del proceso de creación, realización, ejecución y evaluación de las 
políticas públicas; se ha construido principalmente como método del análisis, según lo exponen la mayoría de los autores (Roth, 2002) y es una herramienta que fue propuesta por Jones (1970) como lo cita dicho analista.

Si bien, no necesariamente se presentan de manera secuencial y una después de otra, el compartimiento del proceso, por fases o etapas, facilita tanto el análisis, como también la comprensión de su construcción. Se suele identificar como etapas la definición del problema o situación problemática, la formulación de alternativas de solución, decisión, la implementación de la política pública y su ejecución, para luego evaluarla y reformularla o terminarla.

Quinteros (2014, p.10), citando a Alza (2013), indica que estas fases son: «i). El establecimiento de la agenda pública, o agendación; ii). El diseño de estrategias; iii). La implementación de programas públicos, y; iv) la evaluación de lo realizado».

Ruiz (2001), muestra dichos elementos, en cuadro secuencial (de izquierda a derecha).

Así, entonces, la sociedad representada en grupos de presión, de interés, 0 actores sociales y el Estado-gobierno, definen y agendan el problema o realidad a modificar, para luego junto al grupo social objeto, formular alternativas de propuestas para tomar la decisión que se considera es la respuesta 0 solución a la problemática planteada, la cual debe ser ejecutada, evaluada y de ser necesario se reformula la política.

Ahora bien, también se ha presentado el ciclo de la política pública como un bucle y así Subirats, (2010 p. 44), lo expone, indicando como inicio o arranque, el surgimiento del problema o situación problemática y tiene un aparente final con la evaluación de la política pública; aparente, porque esta última se convierte en insumo para reformularla o terminarla; en el primer caso se continúa con el círculo y en el segundo, pues sería la terminación de la política pública.

Se presenta en el apéndice uno (1)

Este ciclo o bucle, es un marco de referencia y no un esquema rígido. Dicho ciclo presentado de esa manera esquemática, permite visualmente que el investigador o los analíticos de las políticas públicas puedan a primera vista hacerse a una gran idea de la misma, lo que genera que el esquema pueda facilitar su estudio tanto de todo el proceso en general como el de cada etapa en particular.

Siendo el proceso uno de sus elementos de las políticas públicas, que junto a los demás, son interdependientes y hasta simultáneos, el esquema del ciclo ha sido y sigue siendo un instrumento que permite facilitar el análisis, dado que el esquema general de presentación y estudio previo del problema social como su incorporación en la agenda, la formulación de alternativas de solución y su

\begin{tabular}{|c|c|c|c|c|c|c|}
\hline Ítem/Etapa & $\begin{array}{c}\text { Definición } \\
\text { del problema }\end{array}$ & $\begin{array}{c}\text { Formulación de } \\
\text { alternativas }\end{array}$ & Decisión & $\begin{array}{c}\text { Implementación y } \\
\text { Ejecución }\end{array}$ & Evaluación & $\begin{array}{l}\text { Reformulación de las } \\
\text { políticas }\end{array}$ \\
\hline \multirow{3}{*}{ Actividad } & $\begin{array}{l}\text { Demanda } \\
\text { social }\end{array}$ & $\begin{array}{l}\text { Catálogo de } \\
\text { propuestas }\end{array}$ & $\begin{array}{l}\text { Elección de } \\
\text { una o más } \\
\text { alternativas }\end{array}$ & Gestión & \multirow{3}{*}{$\begin{array}{l}\text { Valoración de } \\
\text { efectos }\end{array}$} & \multirow{3}{*}{ Retroalimentación } \\
\hline & \multirow[t]{2}{*}{\begin{tabular}{|c|}
$\begin{array}{c}\text { Situación de } \\
\text { crisis. }\end{array}$ \\
\end{tabular}} & \multirow[t]{2}{*}{$\begin{array}{l}\text { Priorización de } \\
\text { criterios }\end{array}$} & \multirow[t]{2}{*}{ Legitimación } & Prestación & & \\
\hline & & & & $\begin{array}{l}\text { Producción de } \\
\text { efectos }\end{array}$ & & \\
\hline La realiza & $\begin{array}{l}\text { Sociedad/ } \\
\text { Gobierno }\end{array}$ & $\begin{array}{c}\text { Grupo de trabajo } \\
\text { estatal/grupo } \\
\text { social }\end{array}$ & $\begin{array}{c}\text { Autoridad } \\
\text { competente }\end{array}$ & Grupo de ejecución & $\begin{array}{l}\text { Autoridades de } \\
\text { control/ } \\
\text { Autoevaluación }\end{array}$ & $\begin{array}{c}\text { Autoridad responsable de la } \\
\text { política pública }\end{array}$ \\
\hline
\end{tabular}

Adaptada de: Ruiz (2001, p.95). 
adopción, como la ejecución y evaluación, conlleva a que el ciclo desarrollado sea una de las maneras de primera mano para realizar su análisis de manera comprehensiva e integral.

Cabe anotar que la sostenibilidad y conservación del ambiente, se han vuelto un elemento transversal tanto en el proceso como en su definición o decisión y en la ejecución de las políticas públicas.

\section{ACTORES DE LAS POLÍTICAS PÚBLICAS}

Son las personas, individuos, instituciones, grupos, comités, organizaciones sociales de toda naturaleza, el Estado o algunas de sus entidades y en general todo aquel que con su actuar o su inactividad, decisión o determinación, contribuyen 0 aportan con elementos propios de las políticas públicas su creación o implementación, como su desarrollo y ejecución.

Los actores de las políticas públicas son «aquellas personas naturales, jurídicas o grupos organizados, que a través de sus comportamientos hacen posible el desencadenamiento de las acciones y decisiones en torno a una política pública (policy makers). Comprende tanto a individuos, como a organizaciones sociales y públicas, empresas privadas, organismos y organizaciones internacionales entre otros» (Jiménez \& Soler. 2013, p. 37).

Si bien muchos de los aludidos pueden tenerse como actores de política públicas, realmente lo serán si la acción que realizaron ha tenido incidencia cierta o evidente en el proceso de la política pública (Sierra. 2009). Significa lo anterior que es necesario el comportamiento, la conducta e incidencia de quien participa en el proceso de políticas públicas, que se vea reflejada en las fases para que efectivamente sea un actor de esta naturaleza, por lo que potencialmente toda persona de manera individual, colectiva o grupal es apta para ser actor de políticas públicas, pero sólo lo será en la medida que su acción u inacción repercuta en el proceso e impacte en la política pública.

Algunos de los analistas, enlistan y clasifican a la diversidad de actores públicos para facilitar su com- prensión. Figuran de un lado, «los Partidos Políticos, el Gobierno, la Administración Pública, el Congreso, el Presidente y el poder Judicial.» (Subiratas et al. 2010) Y que en el otro lado o sector privado están «los medios de comunicación, los centros de investigación y los Grupos de Interés como la Iglesia, Sindicatos, ecologistas, etc.», dividiendo entonces a los actores entre los del sector público y los del privado, criterio que puede servir como un mero referente para determinar bien que se trata de una política pública por la incidencia del actor tanto en su creación como en su ejecución.

Santibáñez, et al., (s.f), también clasifica los actores de políticas públicas entre actores públicos y actores privados, aclarando que no todos participan de manera simultánea en las etapas de la política pública y lo harán «a medida que sus intereses se vean trastocados de acuerdo al alcance de la política pública». Indica que son actores públicos el gobierno, la administración pública, los partidos políticos y los organismos internacionales; y actores privados, la empresa privada, los grupos de interés, los centros de investigación y los medios de comunicación. Se destaca en esta clasificación a los organismos internacionales, quienes hoy en día son artífices de muchas de las políticas públicas que los Estados Latinoamericanos llevan a cabo.

Ahora bien, la definición de políticas públicas establecida en el artículo 201 de la ley 1098 de 2006, establece como actores de la política pública de adolescencia e infancia el Estado, la Sociedad, la Familia, los niños, las niñas y los adolescentes. Siempre es actor de las políticas públicas el Estado, principalmente el gobierno, los usuarios o beneficiarios sociales, organizaciones no gubernamentales en sus diversas manifestaciones, grupos de presión y de interés, así como medios de comunicación y la diversidad de grupos sociales existentes o que se forman circunstancialmente en la sociedad. También los organismos internacionales.

Si bien el gobierno se tiene como actor principal, las revisiones teóricas actuales aluden más a la gobernanza como «nueva forma de entender las relaciones Estado-sociedad en el marco de las transformaciones estatales» (Natera, 2004); es una 
representación que apunta a la interrelación e interacción entre el gobierno y actores no estatales, internos y externos, y actores económicos en ambientes de cooperación, conciliación y consensos para el logro de compromisos mutuos en diversos ambientes geográficos y políticos.

\section{LOS RECURSOS DE LAS POLÍTICAS PÚBLICAS}

Como todo proceso, el de las políticas públicas, conlleva a que sus diversos elementos, en desarrollo o ejecución de la actividad, deban consumir varios recursos. Por recursos ha de entenderse que son los elementos disponibles para desarrollar el proceso, como la creación o adopción de las políticas públicas, así como su ejecución. Santibáñez et al., (p.13), expone que «son medios e instrumentos que son usados e intercambiados entre los actores de las políticas públicas», indica que pueden ser «financieros, humanos, organizativos y tecnológicos».

Por su parte, Subirats et al., (p. 71), exponen que los recursos eran únicamente el derecho y los económicos y personales, pero que la ciencia de la administración, «ha puesto de relieve que la información, la organización, las infraestructuras públicas, el tiempo y el consenso pueden considerarse también como recursos de políticas públicas»; e indica que para los politólogos, la capacidad de movilización política, es un recurso también. Así entonces enlistan diez (10), pero dejando abierta la posibilidad de la existencia de otros. Reseñan el Derecho (como recurso jurídico); el Personal (como recurso humano); el Dinero (recurso económico); la Información (lo denominan recurso cognitivo); la Organización (recurso interactivo o relacional), el Consenso (denominándolos como recurso confianza); el Tiempo (recurso cronológico); la Infraestructura: (recurso patrimonial); el Apoyo Político (recurso mayoría) y la Fuerza (recurso violencia).

Así, los recursos en políticas públicas son elementos financieros, de información, tecnológicos, normativos, de tiempo, así como el talento humano, que son utilizados por los actores de las políticas públicas en todo el ciclo o proceso de estudio, decisión, adopción, ejecución, evaluación y retroalimentación de las políticas públicas. Todos estos recursos deben ser adecuadamente gestionados o administrados para el logro o propósito de la política pública que es en últimas, la realización de los fines del Estado.

Dicha utilización de recursos debe obedecer a una sostenibilidad y conservación del ambiente, que, como ya se indicará, se ha vuelto un elemento transversal tanto en el proceso como en su definición o decisión y en la ejecución de las políticas públicas.

\section{NORMAS JURÍDICAS Y POLÍTICAS PÚBLICAS}

Las normas jurídicas son normas que contienen un mandato, una orden u obligación, para el destinatario de las mismas, contienen imperium y no existe ni tiene validez si dependiera de la voluntad del receptor u obligado (Araujo, 2008), siendo por tanto característica de estas normas la obligación jurídica y la coacción; esto es que se impone aún por la fuerza y contra la voluntad de quien está obligado, lo que la diferencia de otras normas, como la moral o las normas sociales.

Las normas jurídicas se hallan conformadas por reglas principios y valores; «mientras las reglas son normas que ordenan una consecuencia jurídica definitiva, los principios son mandatos de optimización que ordenan que algo se realice en la mayor medida posible según las posibilidades fácticas y jurídicas.» (Sentencia, C-713/08) y los valores «representan el catálogo axiológico a partir del cual se deriva el sentido y la finalidad de las demás normas del ordenamiento jurídico» (Sentencia T-406/92).

Las normas jurídicas han sido uno de los instrumentos (como elemento que es de las políticas públicas), que utiliza el gobierno -principalmente-, para obtener el inicio, impulso, desarrollo, avance o ejecución de las políticas públicas. Sin embargo la diversidad de actores de las políticas públicas que buscan participar e intervenir en las políticas públicas, han convertido las normas jurídicas, más que un elemento, en un instrumento cardinal en su implementación.

Jiménez \& Soler (2013, p. 123) exponen que existe cuatro puntos de encuentro 0 de controversias entre 
el derecho (normas jurídicas) y los estudios de políticas públicas: i). El enfoque de los derechos humanos; «los derechos humanos se constituyen en el fundamento ético de la formulación y ejecución de políticas públicas»; ii). El control de legalidad; «el ámbito de acción de las políticas parece encontrar límites en los principios, valores y derechos fundamentales establecidos en la constitución o en los tratados internacionales que hacen parte del bloque de constitucionalidad»; iii). El «gobierno de los jueces» quienes a través de sus decisiones vía acciones constitucionales salvaguardan el Estado de Derecho, garantizan los derechos fundamentales con lo que puede hacer que se generen (o adoptar) políticas públicas, y; iv). La política pública como norma jurídica. "Las políticas públicas contienen objetivos y pautas de acción que podrían ser considerados como principios y reglas jurídicas»

El Estado Social de Derecho se desenvuelve en las normas jurídicas y sus finalidades las desarrolla, ejecuta o cumple mediante el ejercicio de las funciones públicas y la prestación de servicios públicos; por tanto, las políticas públicas son manifestaciones de las finalidades estatales, las que se convierten en norma jurídica o beneficios de un servicio público, según se trate de políticas pública relacionada con la función pública o con el servicio público.

Esta perspectiva permite ir más allá de la discusión, no zanjada, de si las políticas públicas son normas jurídicas o realizaciones políticas del gobierno en particular o puntos de encuentro o controversia, como se expuso.

\section{POLÍTICAS PÚBLICAS Y DECISIONES JUDICIALES}

Las decisiones judiciales, constituyen, definen o dan certeza acerca de las garantías, deberes, derechos u obligaciones de las personas; establecen obligaciones de naturaleza jurídica y por tanto son normas jurídicas con efectos particulares (Araujo 2008) por regla general (pues existen las de efectos erga omnes), que de no ser acatadas, tienen la garantía de parte del mismo sistema jurídico de, por vías coactivas, hacerlas cumplir; tienen la característica de tener fuerza de cosa juzgada «por lo cual no son revocables ni modificables por la administración o por el juez mismo, y ni siquiera por el superior cuando ya se han surtido los recursos ordinarios 0 extraordinarios» (Sentencia T-200/04).

La decisión judicial funde en ella la interpretación del ordenamiento o sistema jurídico, que son sus fuentes, lo que realiza el juez a partir de la interpretación de dicho sistema con la utilización de diversas herramientas de hermenéutica jurídica.

En el Estado Social de derecho, el juez ha adquirido un rol relevante que conlleva a que sus decisiones generen nuevas relaciones con las demás ramas y órganos del Estado, como con la sociedad. En ejercicio de la función judicial, le corresponde la interpretación del sistema normativo, que como ya se indicó está constituido por las reglas, principios y valores y en aras de resolver el caso sometido a su definición debe acatar la finalidad del Estado proveyendo $u$ ordenando proveer bienes o servicios de carácter públicos para satisfacer la exigencia problemática sometida a su consideración, lo que lo ha convertido en protagonista actor de políticas públicas.

En efecto, como quiera que varias de las situaciones problemáticas quedan por fuera de la agenda pública (que es el objeto de la actividad gubernamental para darles solución), o pese a estar dentro de ella no tienen la priorización o la atención que desea la comunidad objeto de recibir los bienes 0 servicios, por diversas razones (como la precariedad de la sociedad civil en reclamarla o por ser objeto de contracultura mayoritaria, entre muchas otras); y dado que la Constitución Política ha creado mecanismos judiciales ${ }^{2}$ para que por medios de órdenes

2 En la constitución política colombiana encontramos los siguientes mecanismos acciones judiciales o medios de control:

- Mecanismo de Búsqueda Urgente -Derecho a no ser desaparecido-. Art. 12. (Ley 971 de 2005).

- Hábeas data. Art. 15 (Ley 1266 de 2008 y 1581 de 2012) 
de esa naturaleza se obligue a quienes tienen el deber constitucional o legal de satisfacerlos, los jueces se han transformado en actores de políticas públicas, participando en su ciclo.

Al respecto Cano (2014), expone que la Corte Constitucional «entiende que el diseño de políticas públicas está dirigido...a la satisfacción de la faceta asistencial, prestacional o programática de los derechos. Se trata, por tanto, de una obligación estatal derivada del modelo de Estado Social».

Gómez Pinto (2012), ha indicado que la Corte Constitucional ha expresado que las principales instituciones e instrumentos más destacados de la política económica, que el Estado Colombiano ha diseñado paras solucionar el problema de asignación y adjudicación (de derechos), se encuentra el régimen de transferencias, el sistema de presupuesto nacional y el plan nacional de desarrollo (p. 37).

Lo anterior ha surgido por cuanto las diversas instituciones democráticas han resultado débiles, deficientes, carentes de fuerza, creatividad e innovación para ganar espacios políticos y sociales que ha generado la utilización de los medios de control 0 acciones judiciales para que sean los jueces los que impongas por vía de decisiones judiciales las soluciones a la situación problemática, «lo que en ocasiones ha reeditado la vieja polémica sobre las márgenes de actuación de las instancias judiciales con relación a las instancias políticas». (Abramovich \& Pautassi 2009).

Las necesidades de la población, como salud, educación, vivienda, entre otras, ha sido abordada su solución por parte del Estado por dos vías: como políticas públicas «que hace énfasis en la exigibilidad condicionada a la oportunidad y conveniencia de los poderes representativos: Ejecutivo y Legislativo», y la segunda, por vía jurisdiccional o judicial, por medio de la cual las personas llevan su necesidad (lo denominan conflicto) a un juez para que ampare sus derechos sociales» (Mazabel \& otros 2011).

Como quiera que los ciudadanos consideran que la prestación de bienes y servicios no se prestan adecuadamente, con acceso efectivo o eficiencia razonable o con equidad, pues se violan y desconocen derechos fundamentales han encontrado que los mecanismos judiciales hacen prevalecer estos derechos o derechos colectivos, encontrando entonces que las decisiones judiciales, cuestionan la agenda pública, inciden en ella y hasta la imponen lo que resulta, en muchas oportunidades menos desgastante y más efectivo que a través de mecanismos de participación política.

Lo anterior genera o forja en los jueces «un grado mayor de responsabilidad en la fundamentación y argumentación de sus decisiones, pues el sistema político en su conjunto asume la tensión de no reemplazar arbitrio político por arbitrio judicial» (Abramovich \& Pautassi 2009 p.6)

\section{CONCLUSIONES}

En el presente artículo se ha realizado un recorrido por la temática de las políticas públicas al presentar diversas definiciones para establecer

\footnotetext{
Hábeas corpus. Art. 30 (Ley 1095 de 2006)

Acción de extinción de dominio. Art. 34 (Ley 1708 de 2014)

Acción de tutela. Art. 86 (D. 2591 de 1991)

Acción de cumplimiento. Art. 87 (Ley 393 de 1997)

Acción popular. Art. 88 (Ley 472 de 1998)

Acción de grupo. Art. 88. (Ley 472 de 1998)

- Acción de reparación del daño antijurídico. Art. 90 (Art. 140, Ley 1437 de 2011)

- Acción de repetición. Art. 90. (Ley 678 de 2001).

- Acción de pérdida de investidura Art.184 (Ley 144 de 1994)

Acción de nulidad por inconstitucionalidad. Art. 237-2

- Acción de nulidad electoral. Art. 237-7 (Art. 135 de la Ley 1437 de 2011)

- Acción de inconstitucionalidad. Art. 241 (Decreto 2067 de 1991)

- Acción de nulidad electoral. Art. 264 (Art. 275 a 296 de la Ley 1437 de 2011)
} 
lo que son y no son políticas públicas y así evitar asimilar que todo lo que hace es gobierno, o el ente estatal, se entienda como si se tratara de políticas públicas.

Igualmente, se expone los elementos de las políticas públicas que permiten su caracterización, identificación como su conocimiento en el análisis que de ellas se realice; se alude al ciclo, que suele haber en una política pública como herramienta utilizada para efectuar el análisis de su génesis, desarrollo su evaluación y retroalimentación, junto con la conceptualización de lo que son los actores de las políticas públicas, donde se ha expuesto el surgimiento con ímpetu de los jueces bajo el nuevo rol que les corresponde ejecutar en el Estado Social de Derecho.

Los recursos utilizados en las políticas públicas y dentro de los cuales la información y el tiempo constituyen recursos importantes, deben responder a una sostenibilidad y conservación del ambiente, como elementos transversales tanto en el proceso como en su definición o decisión y en la ejecución de las políticas públicas.

En el Estado Social de Derecho la discusión, no zanjada, de si las políticas públicas son normas jurídicas o realizaciones políticas se expone que son manifestaciones de las finalidades estatales, las que se convierten en norma jurídica o beneficios de un servicio público, según se trate de una políticas publica relacionada con la función pública 0 con el servicio público respectivamente.

Finalmente, al considerar los ciudadanos que la prestación de bienes y servicios no se proporcionan adecuadamente 0 ni siquiera existen, con los cual se violan y desconocen derechos fundamentales o colectivos, acuden a que se dicten decisiones judiciales, con las que logran incidir 0 imponer en la agenda pública, la solución a situaciones problemáticas sin el desgaste del activismo político; sin embargo, el sistema político entra en tensión entre la prelación del arbitrio judicial en detrimento del político lo que genera en la judicatura un alto grado de responsabilidad en la motivación de sus providencias.

\section{REFERENCIAS BIBLIOGRÁFICAS}

- Abramovich, V. (2009). La revisión judicial de las políticas sociales. Buenos Aires: Editores del Puerto s.r.l.

- Cuervo Restrepo, J. (2007). Las políticas públicas: entre los modelos teóricos y la práctica gubernamental (una revisión a los presupuestos teóricos de las políticas públicas en función de su aplicación a la gestión pública colombiana. En U. E. Colombia, Ensayos sobre Políticas Públicas (Primera ed., págs. 67-95). Bogotá: Universidad Externado de Colombia.

- Gómez, P. (2012). El Juez de las Políticas Públicas. Bogotá: Grupo Editorial Ibáñez.

- Jiménez, W. G. \& Soler, I. (2013). Manual para el estudio y análisis de las políticas públicas y la gobernabilidad. Bogotá: Grupo Editorial Ibáñez.

- Roth Deubel, A.-N. (2002). Políticas Públicas. Formulación, implementación y evaluación (Primera Edición ed.). Bogotá, Colombia: Ediciones Aurora.

- Sierra Cadena, G. (2009). El Juez Constitucional: un actor regulador de las políticas públicas. Bogotá: Universidad del Rosario.

- Subirats, J., Knoepfel, P., Larrue, C., \& Varone, y. F. (2010). Análisis y gestión de políticas públicas (Segunda reimpresión ed.). Barcelona: Ariel.

\section{PÁGINAS WEB}

- $\quad$ Aguirre Torres, Y. (2014). Las políticas públicas de responsabilidad social empresarial en la alcaldía municipal de Mosquera. Recuperado el 20 de abril de 2015, de http://repository. unimilitar.edu.co/bitstream/10654/11753/1/ Politicas\%20Publicas\%20RSE.pdf

- Alcaldía de Bogotá. (s.f.). Guía para la formulación, implementación y evaluación de políticas públicas distritales. Recuperado el 23 de abril de 2015, de http://www.alcaldiabogota.gov.co/ sisjur/adminverblobawa?

- Ayala Pérez, J. (2014). Fundamentos de política pública en medio ambiente en Colombia. Recuperado el $1^{\circ}$ de Abril de 2015, de http:// repository.unimilitar.edu.co/bitstream/10654/ 12340/1/Trabajo \%20a\%20la $\% 20$ fecha $\%$ 2018\%20de\%20junio-\%20ultimo.pdf 
- Bitar, M. (2006). La constitución de la agenda y el ciclo de políticas públicas. Recuperado el 20 de abril de 2015, de http://iguana.fts.uner. edu.ar/ secretarias/academica/catedras_en_linea/ politica_social/documentos/estado_y_ politicas_publicas_y_sociales/La_construccion_ de_la_agenda_Bitar.pdf

- Cano, L. (2014). La narrativa de las políticas públicas en la jurisprudencia de la Corte Constitucional colombiana. Papel Político, 19(2). Recuperado el 20 de abril de 2015, de http:/l dx.doi.org/10.11144/Javeriana.PAP019-2.nppj

- Departamento del Quindío. (29 de 07 de 2011). Políticas Públicas. Recuperado el 1 de Abril de 2015, de http://quindio.gov.co/home/docs/items/ item_100/P-PLA-06PoliticasPublicas.pdf

- Dorantes, G. L. (2008). La construcción de la agenda de poder. Recuperado el 20 de abril de 2015, de Revista Mexicana de Ciencias Políticas y Sociales. Vol. 50, No 204: http.unam.:// revistas mx/index.php/rmspys/issue/view/3415

- García, S. (2007). La Nueva Gestión Pública: Evolución y tendencias. (I. d. Fiscales., Ed.) Recuperado el 25 de abril de 2015, de Presupuesto y Gasto Público 47/2007 37-64: http://www.ief.es/ documentos/recursos/publicaciones/revistas/ presu_gasto_publico/47_GarciaSanchez.pdf

- Gómez Trujillo, C. (2014). Políticas públicas en educación en zonas fronterizas». Recuperado el $1^{\circ}$ de Abril de 2015, de Revista Justicia, No. 25 pp. 171-179 - Universidad Simón Bolívar - Barranquilla, Colombia - ISSN: 0124-7441: http:// publicaciones.unisimonbolivar.edu.co/rdigital/justicia/index.php/justicia/article/viewFile/270/251

- Grisales, L. (2008). Políticas públicas vigentes en Colombia que contribuyen al logro de los objetivos de desarrollo del milenio afines con el sector salud, 2006. Recuperado el 23 de abril de 2015, de http://www.scielo.org.co/pdf/rfnsp/ v26n1/v26n1a09

- Jiménez, B. W. (s.f.). El Enfoque de los Derechos Humanos y las Políticas Públicas. Recuperado el 20 de abril de 2015, de http:// www.usergioarboleda.edu.co/civilizar/revista12/ enfoque_DDHH.pdf

- Macedo, B. (2005). El concepto de sostenibilidad. Recuperado el 22 de abril de 2015, de http:/l unesdoc.unesco.org/images/0016/001621/ 162177S.pdf

- Maggiolo, I., \& Maggiolo, J. P. (2007). Políticas públicas: proceso de concertación Estado-Sociedad. (U. d. Zulia, Ed.) Recuperado el 31 de marzo de 2015, de http://www.produccion cientifica.luz.edu.ve/index.php/rvg/article/view/ 10466/10454

- $\quad$ Mazabel, P. R., Azcarete, L., \& Castellanos, J. L. (2011). La Jurisdicción constitucional como garante de los derechos económicos sociales y culturales «DESC». En C. E. Velandia, Estudios de Derecho Procesal Constitucional Tomo II (págs. 361-402). Bogotá: VC Editores Ltda.

- Ministerio de Salud y Protección Social. (29 de junio de 2012). Política pública nacional para las familias colombianas 2012-2022. recuperado el 21 de abril de 2015, de http://www.eafit.edu.co/ minisitios/derecho-genero-sexualidad/Documents/ APolitica\%20P ublica\%20Familias\% 20Colombianas $\% 202012-\% 202022 \% 20 \% 281 \% 29$.pd

- Natera, A. (2004). la noción de gobernanza como gestión pública participativa y reticular. Recuperado el 22 de Mayo de 2015, de http://e-archivo. uc $3 \mathrm{~m}$. es/bitstream/handle/10016/590/cpa 040202. pdf;jsessionid=96C5C2391670A5EFCE6 CFE687EA3DE17? sequence $=1$

- Quinteros Marquina, V.(2014). Política de extradición: innovaciones al procedimiento de extracción aplicado a altos funcionarios del Estado: el caso Fujimori. Recuperado el $1^{\circ}$ de Abril de 2015, de Pontificia Universidad Católica del Perú. Escuela de Posgrado: http://repository. unimilitar.edu.co/bitstream/10654/12340/1/ Trabajo $\% 20$ a $\% 20$ la $\% 20 f e c h a \% 2018 \% 20$ de $\%$ 20junio-\%20ultimo.pdf

- Rincón Becerra, M. (2014). Algunos elementos teóricos de las políticas públicas: análisis para su formulación. (U. d. Zulia, Ed.) Recuperado el $1^{\circ}$ de abril de 2015 , de Revista Venezolana de Gerencia (RVG) Año 19. No 67: file:///D:/ MIS\%20DOCUMENTOS/

- Ruiz Medina, M. I. (marzo de 2011). «Políticas públicas en salud y su impacto en el seguro popular en Culiacán, Sinaloa, México». Recuperado el 9 de abril de 2015, de http:// www.eumed. net/tesis-doctorales/2012/mirm/ciclo_funcionamiento.html 
- Santibáñez H, A., Barra R., M., \& Ortiz M., P. (s.f.). La Racionalidad de los actores en políticas públicas: Un esquema teórico para entender el funcionamiento de las democracias modernas. Recuperado el 6 de abril de 2015, de http:/ /www.colpos.mx/tabasco/diplomado/ 3y4demarzo/actores_en_politica.pdf.

- Santibáñez H, A., Barra R., M., \& Ortiz M., P. (s.f.). La Racionalidad de los actores en políticas públicas: Un esquema teórico para entender el funcionamiento de las democracias modernas. Recuperado el 6 de abril de 2015, de http: //www.colpos.mx/tabasco/diplomado// actores_en_politica.pdf.

- Tassara, C. (2014). Políticas públicas, cohesión social y desarrollo local: La experiencia europea y los aportes de la cooperación eurolatinoamericana. Recuperado el $1^{\circ}$ de Abril de 2015, de Perfil de Coyuntura Económica No. 23, julio 2014, pp. 15-36 @ Universidad de Antioquia.: http://www.scielo.org.co/pdf/pece/n23/ n23a02.pdf

- Vargas, V. (1996). Las políticas públicas entre la racionalidad técnica y la racionalidad política. En A. varios, Dimensiones Político-económicas del nuevo orden constitucional (Primera ed., págs. 41-60). Santa fe de Bogotá D.C.: Universidad Nacional.

- Velásquez G., R. (Semestres I de 2009). revistas.urosario.edu.co/index.php/desafios/ article/download/433/377. Recuperado el $1^{\circ}$ de abril de 2015, de file://ID:/MIS\%20 DOCUMENTOS/Downloa ds/433-1513-1-PB.pd

\section{REFERENCIAS JURISPRUDENCIALES}

- $\quad$ CConst, T -476/ 2008, J. Araujo.

- CConst, T-406/1992, C. Angarita.

- CConst, C-713/2008, C. Vargas.

APÉNDICE. Ciclo de las políticas públicas.
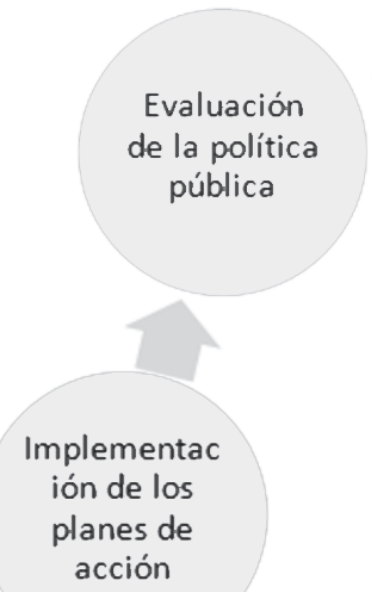

Decisión y adopción de un programa legislativo

Fuente: Subirats, K, L \& v (2010 pp 44),

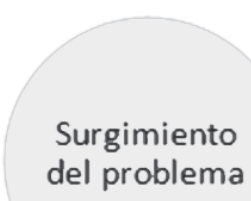

del problema

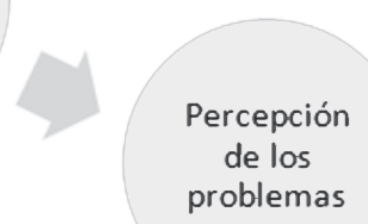

Formulación

de

alternativas 